\title{
"One-shot" analysis of wine parameters in non-Saccharomyces large-scale alcohol reduction processes with one- and two-dimensional nuclear magnetic resonance
}

\author{
J.E. Herbert-Pucheta ${ }^{1}$, C. Pino-Villar² ${ }^{2}$ F. Rodríguez-González ${ }^{3}$, G. Padilla-Maya ${ }^{4}$, D. Milmo-Brittingham ${ }^{4}$, \\ and L.G. Zepeda-Vallejo ${ }^{5}$ \\ ${ }^{1}$ Consejo Nacional de Ciencia y Tecnología-Laboratorio Nacional de Investigación y Servicio Agroalimentario y Forestal, Universidad \\ Autónoma Chapingo, Carretera México-Texcoco Km 38.5, C.P. 56230, Chapingo, Estado de México, Mexique \\ ${ }^{2}$ Monte Xanic, Lago Tangañica No. 18, Colonia Granada, Municipio Miguel Hidalgo, CP 11520, Ciudad de México, Mexique \\ ${ }^{3}$ Casa Madero, Carretera Paila 102- Parras Km. 18.2; Hacienda San Lorenzo. Parras de la Fuente, C.P. 27980, Coahuila, Mexique \\ ${ }^{4}$ Consejo Mexicano Vitivinícola A.C. Montecito No 38 Piso 15 Despacho 22 - WTC México, C.P. 03810, Ciudad de México, Mexique \\ ${ }^{5}$ Departamento de Química Orgánica, Escuela Nacional de Ciencias Biológicas, Instituto Politécnico Nacional, Prolongación de Carpio \\ y Plan de Ayala s/n, Colonia Santo Tomás, 11340 Ciudad de México, Mexique
}

\begin{abstract}
Facing climate change in wine industry comprises the implementation of strategies, such as to reduce alcohol in wines, promoted by abnormal increment of sugar levels in wine grapes. The present work discusses the first industrial-scale use of specific yeast strains able to produce wine with reduced alcoholic concentration. Reduction of alcohol content and quantification of key metabolites associated to oenological practice and/or quality were simultaneously measured in a "one-shot" way with proton Nuclear Magnetic Resonance Spectroscopy. Novel relevant metabolites were revealed with the use of a two-dimensional ${ }^{1} \mathrm{H}_{-}{ }^{13} \mathrm{C}$ HSQC multipresat correlation spectroscopy, whereas a detailed methodological NMR description is stressed, towards revealing novel resonances within the NMR signature. The use of multitask analytical methods to simultaneously describe alcohol reduction and NMR targeting, completes the portfolio of NMR solutions recently proposed to the World Organisation of Vine and Wine for as well quantify aging and varieties.
\end{abstract}

\section{Introduction}

Current oenological practices are focused in searching strategies for reducing alcohol content in wine, as climate changes has provoked an important increase of sugar amounts in must. With the simplest Saccharomyces yeast strains anaerobic conditions, fermentation of grapes with increased sugar content will produce wine with high alcohol by volume percentage $(\% \mathrm{ABV})$ and thus a product with penalized mouth-feel and/or taint and/or flavour [1,2]. In consequence, an important reduce of market consumption or severe tax government policies, could be expected. Amongst the broad spectrum of viticultural, physical or microbiological processes suggested for alcohol reduction, the concatenated use of non-Saccharomyces yeast strains to first aerobically sequester excess of sugar content by respiration, followed by the use of anaerobic Saccharomyces strains for final fermentation, has gained attention in the last years [3-5]. Methods comprising the use of several nonSaccharomyces yeast strains for assimilating must sugar to produce wine with reduced alcohol content and appropriate organoleptic properties has been extensively reported at lab- medium- and pilot-scales [6-8], but scarcely reported at industrial scale [9]. Finally, analysis of relevant wine parameters of reduced alcohol wines is carried out currently by a set of different enzymatic colorimetric trials and chromatographic schemes. Basic wine analysis comprises the quantification of primary metabolites such as ethanol, acetic acid, D-glucose, D-fructose, glycerol, lactic acid, malic acid and/or isovaleric acid -each with a particular enzymatic test kit-, that present some disadvantages such as time consuming; they present certain complexity in terms of sample preparation and chemical manipulations, they are costly and require some level of analytical expertise.

The present work proposes a "one-shot" evaluation of basic dealcoholized wine parameters with one- and two-dimensional Nuclear Magnetic Resonance (NMR) fingerprint and profiling [10-12]. Mono-varietal Mexican Cabernet Sauvignon wines with reduced alcohol content, were prepared in a large-scale regime (3.0 Ton grape, final volume of c.a. 2900 L) with non-Saccharomyces Candida zeplina strain, in co-inoculation with $S$. cerevisiae for final fermentation. Said reducing alcohol content procedure, was compared with at least two alcoholic fermentations at the same scale, carried out respectively with $S$. bayanux or S. cerevisiae (CM) strains. Ethanol reduction with simultaneous profiling and quantification of key metabolites such as acetic acid, malic acid, sorbic acid, fumaric acid and shikimic acid were carried out with a recent OIV procedure [10]. Finally, the use of 2D-NMR acquisition schemes are proposed in order to increase 
Table 1. Degrees Brix, acidity $(\mathrm{pH})$ and total acidity (T.A.) of selected Cabernet Sauvignon grapes from MX and CM, used for large scale fermentations.

\begin{tabular}{|l|l|l|l|}
\hline Site & Brix $\left({ }^{\circ}\right)$ & $\mathrm{pH}$ & T.A. $(\mathrm{g} / \mathrm{L})$ \\
\hline $\mathrm{MX}$ & 23.0 & 3.68 & 5.53 \\
\hline $\mathrm{CM}$ & 23.8 & 3.65 & 6.4 \\
\hline
\end{tabular}

Table 2. Microbiological and oenological characteristics of the Non-Saccharomyces Candida zemplinina strain, used in sequential inoculation, for reduction of wine alcohol content in the present large-scale trial.

\begin{tabular}{|l|l|}
\hline Fermentation temperature & $15-26^{\circ} \mathrm{C}$ \\
\hline Fermentation velocity & Slow \\
\hline Alcohol tolerance & $\leq 10 \% \mathrm{v} / \mathrm{v}$ \\
\hline $\mathrm{SO}_{2}$ resistance & $<20 \mathrm{ppm}$ free \\
\hline Volatile acidity (VA) production & $\begin{array}{l}20-30 \% \text { less than } \\
\text { S. cerevisiae }\end{array}$ \\
\hline Glycerol production & Very high \\
\hline $\mathrm{H}_{2} \mathrm{~S}$ production & Very low \\
\hline $\mathrm{SO}_{2}$ production & Very low \\
\hline $\mathrm{Nitrogen}$ need & Not Specified \\
\hline
\end{tabular}

the number of observables for quantifying efficiency of alcohol reduction, with a set of additional parameters so far not explored.

\section{Materials and methods}

\subsection{Large scale fermentations}

Large scale production of wine with reduced Alcohol content $(\%$ alc. v/v) was carried out in two different regions: Baja California, Mexico (Monte Xanic, hereinafter called as MX) and Parras, Coahuila, Mexico (Casa Madero, hereinafter called as $\mathbf{C M}$ ), using the variety Cabernet Sauvignon, obtaining yields of c.a. $2950 \mathrm{~L}$ of wine, using as raw material 3.0 Ton Cabernet Sauvignon grapes. Prior to vinification, used grapes presented the following chemical properties, resumed in Table 1.

Large-scale alcohol reduction were done with the following non-conventional strains (Tables 2-4), whereas results will be compared against a large-scale control process (Saccharomyces bayanus, Strain 10N45).

Large scale fermentations herein developed, can be resumed as:
A. Standard Saccharomyces bayanus, Strain 10N45.
B. Co-inoculation Non-Saccharomyces Candida zem- plinina (Enartis Ferm) + S. cerevisiae 10N45
C. Inoculation w/Saccharomyces Bayanus ex uvarum ES-U42 (Enartis Ferm)
D. Inoculation w/Saccharomyces cerevisiae (IONYS).

\subsection{Nuclear magnetic resonance (NMR) spectroscopy}

Sample preparation for NMR studies comprised the addition of $100 \mu \mathrm{L}$ of a mixture of $\mathrm{D}_{2} \mathrm{O}$ and chemicalshift reference sodium 3-(trimethylsilyl)-propionate-2, 2, 3, $3-\mathrm{d}_{4}$ (TSP), phosphonate buffer $\mathrm{KH}_{2} \mathrm{PO}_{4} 0.1 \%$ and $2 \%$
Table 3. Microbiological and oenological characteristics of the Saccharomyces Bayanus ex uvarum ES-U42 strain, used for reduction of wine alcohol content in the present large-scale trial.

\begin{tabular}{|l|l|}
\hline Fermentation temperature & $\begin{array}{l}15-20^{\circ} \mathrm{C} \\
\left(<25^{\circ} \mathrm{C} \text { for red wines }\right)\end{array}$ \\
\hline Fermentation velocity & Moderate at low temperatures \\
\hline Alcohol tolerance & $\leq 16 \% \mathrm{v} / \mathrm{v}$ \\
\hline $\mathrm{SO}_{2}$ resistance & High \\
\hline Volatile acidity (VA) production & Very low $(<0.25 \mathrm{~g} / \mathrm{L})$ \\
\hline Glycerol production & Very high \\
\hline $\mathrm{H}_{2} \mathrm{~S}$ production & Medium \\
\hline $\mathrm{SO}_{2}$ production & Low \\
\hline $\mathrm{Nitrogen}$ need & $150 \mathrm{~g} / \mathrm{hL}$ of YAN \\
\hline Oxygen need & Medium-low \\
\hline
\end{tabular}

Table 4. Microbiological and oenological characteristics of the Saccharomyces cerevisiae IONYS strain, used for reduction of wine alcohol content in the present large-scale trial.

\begin{tabular}{|l|l|}
\hline Fermentation temperature & $25-28{ }^{\circ} \mathrm{C}$ \\
\hline Fermentation velocity & Slow and constant \\
\hline Alcohol tolerance & $15.5 \% \mathrm{v} / \mathrm{v}$ \\
\hline $\mathrm{SO}_{2}$ resistance & Not Specified \\
\hline Volatile acidity (VA) production & Very low \\
\hline Glycerol production & Very high (up to $15 \mathrm{~g} / \mathrm{L}$ ) \\
\hline $\mathrm{H}_{2} \mathrm{~S}$ production & Not Specified \\
\hline $\mathrm{SO}_{2}$ production & Low \\
\hline Nitrogen need & Very high \\
\hline Oxygen need & NE \\
\hline
\end{tabular}

$\mathrm{NaN}_{3}$ to $900 \mathrm{uL}$ of wine sample, whereas $\mathrm{pH}$ was finally adjusted to a value of 3.9 for all samples. Samples were finally versed in standard $5 \mathrm{~mm}$ NMR tubes.

All spectra were recorded on a Bruker 600 AVANCE III HD equipped with a $5 \mathrm{~mm}{ }^{1} \mathrm{H} / \mathrm{D}$ TXI probehead with z-gradient. The following set of NMR experiments were conducted at a temperature of $298 \mathrm{~K}$, stabilizing the temperature with a Bruker VCU flow unit:

a) Quantitative one-dimensional proton nuclear magnetic resonance spectra (q-1D- $\left.{ }^{1} \mathrm{H}-\mathrm{NMR}\right)$ used to measure the reduction of alcoholic content in wines were carried out by recording a total of 64 transients, that were collected into 28,844 complex data points, with a spectral width of $20 \mathrm{ppm}(12019 \mathrm{~Hz})$, an optimized recovery delay of 5.6 seconds to obtain quantitative signal integration and acquisition times of $1.2 \mathrm{~s}$, produced experimental times of 7 minutes per experiment. No apodization function was used prior to Fourier Transformation.

b) $1 \mathrm{D}-{ }^{1} \mathrm{H}$ experiments with water-to-ethanol solvent presaturation were carried out as elsewhere reported [12].

c) Two-dimensional ${ }^{1} \mathrm{H}_{-}{ }^{13} \mathrm{C}$ Heternouclear Single Quantum Coherence experiment [13] with a homemade water-to-ethanol multipresaturation scheme [12], prior to INEPT polarization transfer [14] were recorded by acquiring $7810 \times 256$ points with 32 

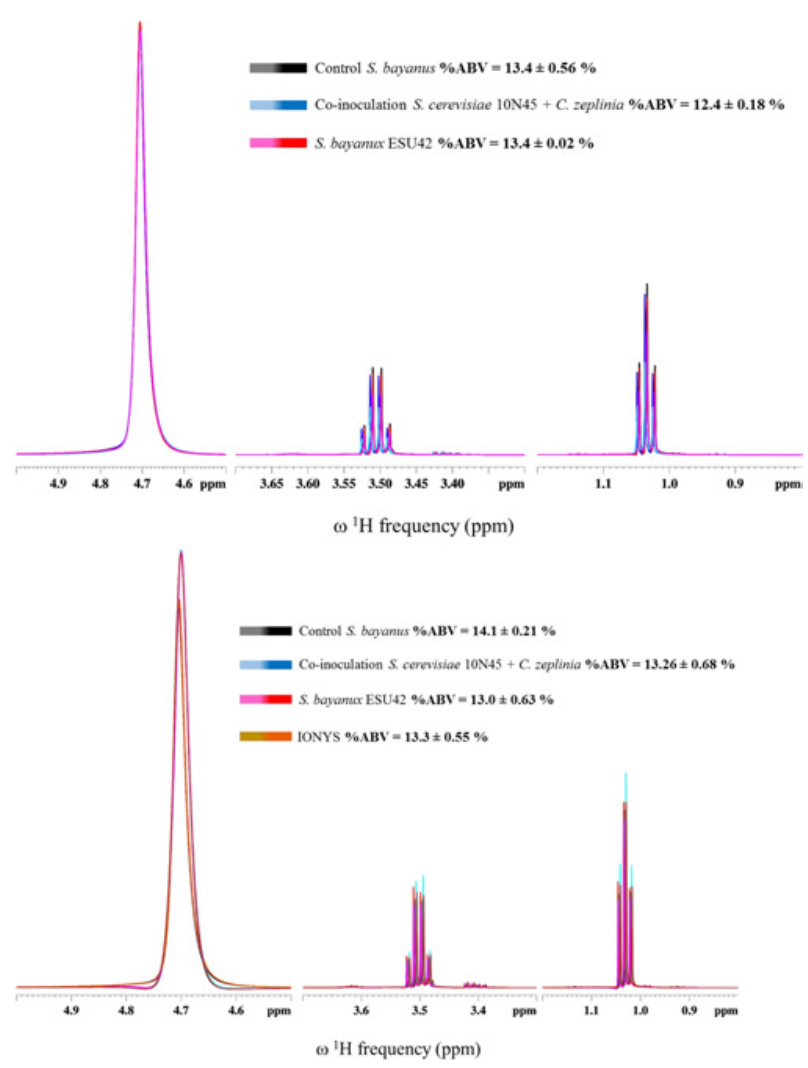

Figure 1. Quantitative one-dimensional proton nuclear magnetic resonance (q-1D- ${ }^{1} \mathrm{H}$ NMR) spectra of large-scale fermented wine samples of MX (top) and CM (bottom) obtained with: standard S.bayanus as control (black); Non-Saccharomyces Candida zemplinina + S. cerevisiae 10N45 (blue); Saccharomyces Bayanus ex uvarum ES-U42 (pink) and Saccharomyces cerevisiae (IONYS, brown).

scans per transient. Heteronuclear ${ }^{1} \mathrm{H}^{-13} \mathrm{C}$ spectral widths were setup respectively at $20\left({ }^{1} \mathrm{H}\right), 180$ $\left({ }^{13} \mathrm{C}\right) \mathrm{ppm}$. With acquisition times for the direct F2 dimension of $325 \mathrm{~ms}$ and a recovery delay of $1 \mathrm{~s}$. produced experimental times of $3 \mathrm{~h} 18 \mathrm{~min}$ per HSQC experiment.

\section{Results and discussion}

Q-1D- ${ }^{1}$ H-NMR spectra of full set of samples (Fig. 1) were obtained in order to calculate \%alc. ( $v / v)$ of each fermented product, by means of signal integration of methyl $(\delta=$ $1.026 \mathrm{ppm}$, triplet)-to-methylene ( $\delta=3.497 \mathrm{ppm}$, quartet) signals, with respect water signal $(\delta=4.7 \mathrm{ppm}$, singlet). Direct percentage of integrated methylene signal $(\delta=$ $3.497 \mathrm{ppm}$, quartet), with respect integrated $\mathrm{H}_{2} \mathrm{O}$ signal ( $\delta=4.7 \mathrm{ppm}$, singlet), immediately provides the alcohol percentage of fermented samples, as methylene and water signals present both the same number of observed spins $(I=2)$. Alcohol reduction of each large scale trial, computed by q-1D- ${ }^{1} \mathrm{H}-\mathrm{NMR}$ was of around $1 \%$ in all cases (see Fig. 3), as expected and verified by crosscheck methods. In the other hand, multipresat $1 \mathrm{D}-{ }^{1} \mathrm{H}-$ NMR experiments will serve to detect and quantify appropriate metabolites such as acetate $(1.9-1.92 \mathrm{ppm})$, malate $(2.45-2.48 \mathrm{ppm})$, sorbate $(5.84-5.87 \mathrm{ppm})$, fumaric $(6.65-6.61 \mathrm{ppm})$ and shikimic $(6.68-6.69 \mathrm{ppm})$

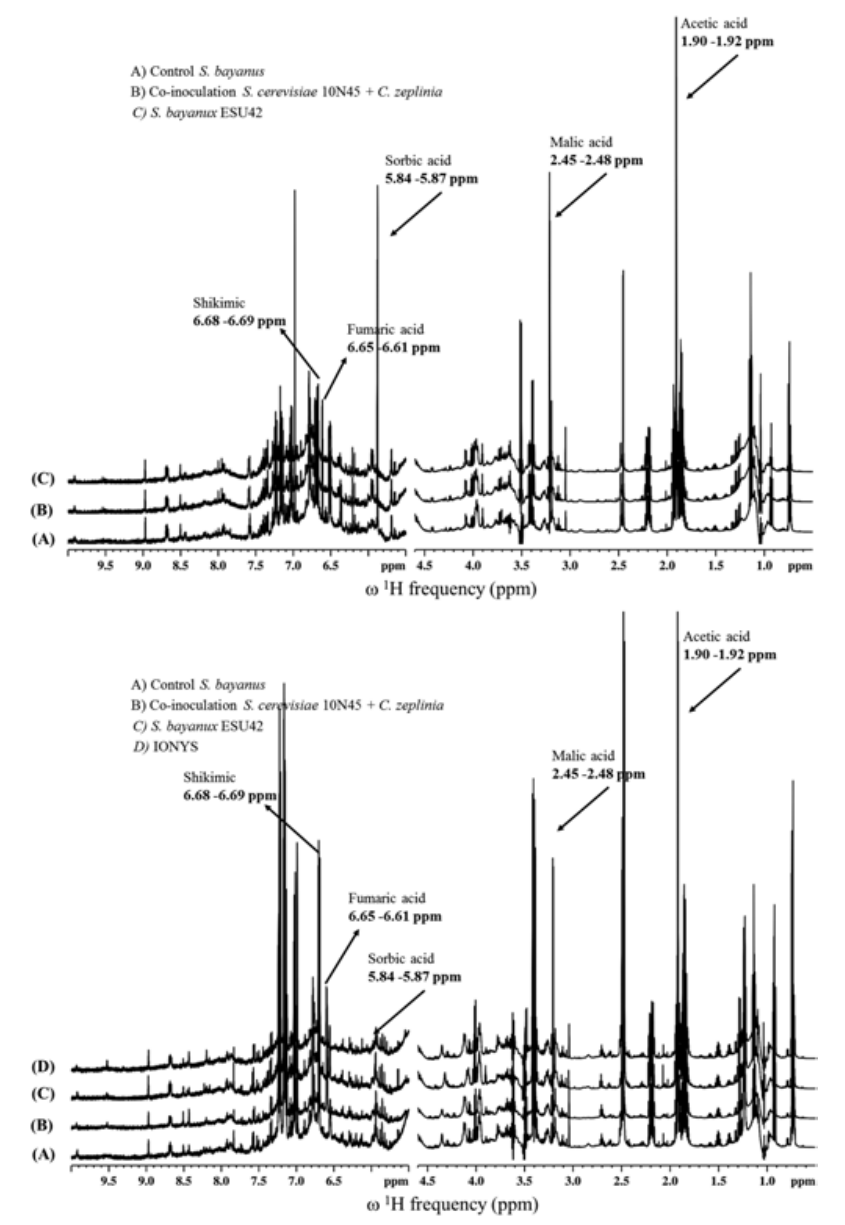

Figure 2. Stacked proton one-dimensional Nuclear Magnetic Resonance spectra $\left({ }^{1} \mathrm{H}-\mathrm{NMR}\right)$ with improved water-to-ethanol multipresat. Scheme [12] of Mexican monovarietal Cabernet Sauvignon wines, with different large-scale fermentations (A to D fermentation processes, see Materials and Methods, see as well Figure legends). Top: stacked $1 \mathrm{D}^{-1} \mathrm{H}$ NMR from Monte Xanic; Bottom: stacked 1D- ${ }^{1} \mathrm{H}$ NMR from Casa Madero. NMR signature of Mexican Cabernet Sauvignon shows the signal assignment of relevant metabolites prone to be quantified by the PULCON/NMR-OIV method [10,15].

by the PUlse Length based CONcentration (PULCON) method [15].

Detection and quantification of acetate, malate, sorbate, fumaric and shikimic moieties from the NMR signature is related to the easiness for signal selection of isolated-intense resonances from above mentioned metabolites, even exposed within the q-1D- ${ }^{1} \mathrm{H}-\mathrm{NMR}$ spectra, without multipresat scheme (Fig. 1), but at low signal-to-noise ratio. However, novel schemes involving solvent elimination and addition of a second dimension for dispersing encumbered resonances from the $1 \mathrm{D}-{ }^{1} \mathrm{H}$ fingerprint will shed light in novel resonances or exposed regions, potentially ready to be quantified with PULCON/NMR procedures. For that it is presented the use of a two-dimensional ${ }^{1} \mathrm{H}^{13} \mathrm{C}$ Heternouclear Single Quantum Coherence (HSQC) experiments, applying a home-made water-to-ethanol multipresaturation scheme [12] for assigning novel resonances involving relevant metabolites associated to oenological practices or quality control parameters. 


\section{$\%$ alcohol (v/v)}

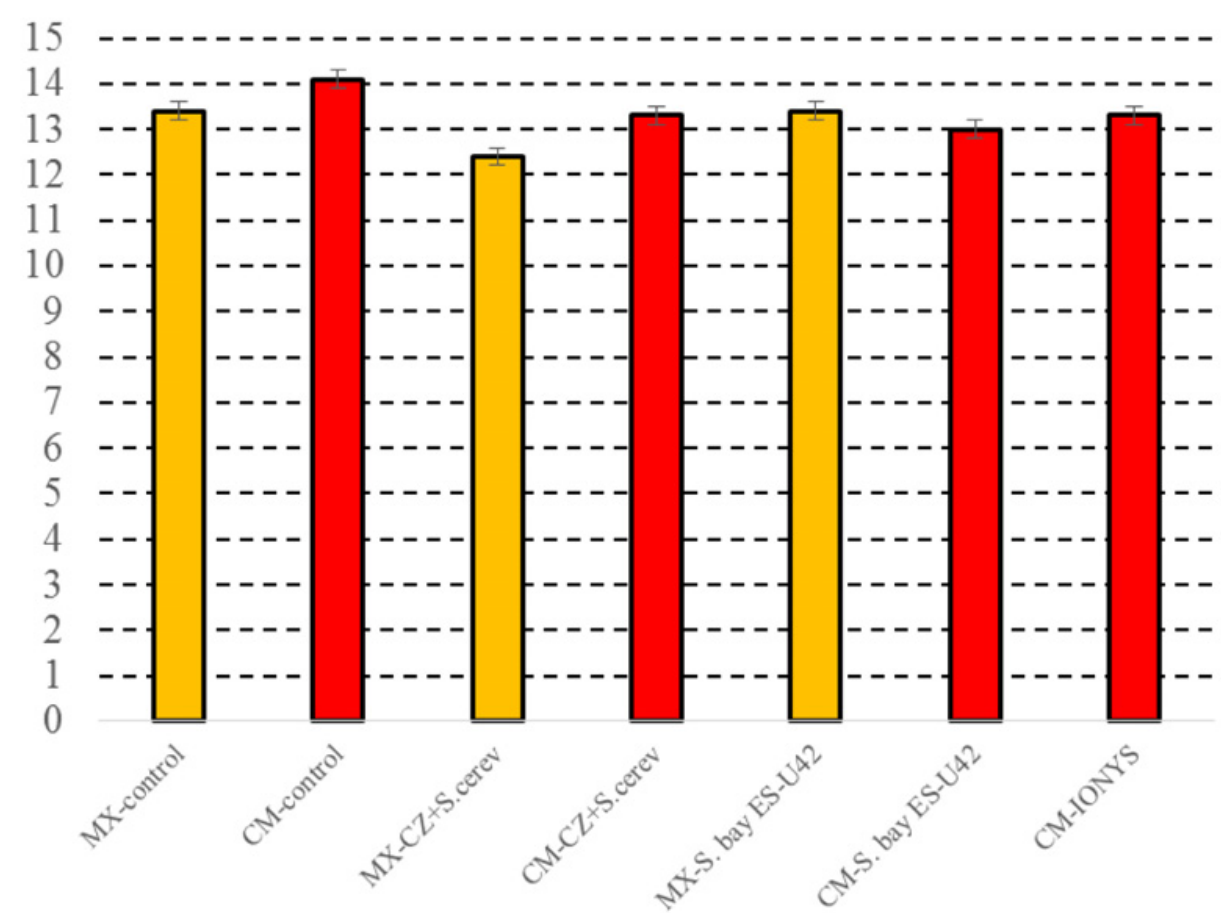

Alcohol reduction with respect controls

\begin{tabular}{|l|c|c|c|}
\hline Site & $\begin{array}{l}\text { Non-Saccharomyces } \\
\text { Candida zemplinina }+ \\
\text { 10N45 S. cerevisiae }\end{array}$ & $\begin{array}{c}\text { Saccharomyces } \\
\text { Bayanus ex } \\
\text { uvarum ES-U42 }\end{array}$ & $\begin{array}{l}\text { Saccharomyces } \\
\text { cerevisiae IONYS }\end{array}$ \\
\hline $\begin{array}{l}\text { Monte } \\
\text { Xanic }\end{array}$ & $\mathbf{1 . 0} \%$ & $\mathbf{0 . 0 \%}$ & - \\
\hline $\begin{array}{l}\text { Casa } \\
\text { Madero }\end{array}$ & $\mathbf{0 . 8 \%}$ & $\mathbf{1 . 1 \%}$ & $\mathbf{0 . 8 \%}$ \\
\hline
\end{tabular}

\begin{tabular}{|l|r|r|r|r|r|}
\hline & \%Alc. (v/v) & \multicolumn{1}{l|}{$\mathrm{pH}$} & $\mathrm{TA}(\mathrm{g} / \mathrm{L})$ & $\mathrm{VA}(\mathrm{g} / \mathrm{L})$ & free $\mathrm{SO}_{2}(\mathrm{mg} / \mathrm{L})$ \\
\hline MX-control & $\mathbf{1 3 . 4}$ & 4.03 & 3.94 & 0.34 & 22 \\
\hline CM-control & $\mathbf{1 4 . 1}$ & 3.7 & 5.5 & 0.49 & 25 \\
\hline MX-CZ+S.cerev & $\mathbf{1 2 . 4}$ & 4 & 4.06 & 0.42 & 23 \\
\hline CM-CZ+S.cerev & $\mathbf{1 3 . 3}$ & 3.65 & 5.6 & 0.49 & 32 \\
\hline MX-S. bay ES-U42 & $\mathbf{1 3 . 4}$ & 4.02 & 4.73 & 0.53 & 27 \\
\hline CM-S. bay ES-U42 & $\mathbf{1 3}$ & 3.81 & 5.4 & 0.56 & 28 \\
\hline CM-IONYS & $\mathbf{1 3 . 3}$ & 3.64 & 5.8 & 0.54 & 33 \\
\hline
\end{tabular}

Figure 3. Alcohol reduction (with respect standard S.bayanus controls), wines' final pH, Total Acidity (T.A.), Volatile Acidity (V.A.) and free sulphites of large-scale fermentation trials.

Set of novel assigned resonances with the use of twodimensional ${ }^{1} \mathrm{H}-{ }^{13} \mathrm{C}$ HSQC are: tyrosine, phenylalanine, fructose, glycerol, glutamine, lactic acid and quercetin. Assignments were done by confirming a ${ }^{1} \mathrm{H}$-resonance with its correlation to a specific ${ }^{13} \mathrm{C}$ chemical shift. It is worth noting to highlight as example that quercetin proton resonance (6.68 to $6.77 \mathrm{ppm}$ ) present a shift as a function of large-scale fermentation scheme. Despite the last, the easiness to identify quercetin relies on the unambiguous carbon correlations $\left(\delta^{13} \mathrm{C}=116\right.$ and $\left.137 \mathrm{ppm}\right)$ with shifted protons, proving though the advantages of using additional NMR dimensions.

Quantification with PULCON/NMR method consists in referring the signal integral of an unambiguously assigned resonance (or set of them), with respect signal intensity and line width of a known external reference, prepared at chemical conditions close to the sample of unknown concentration. Set method has been proposed 

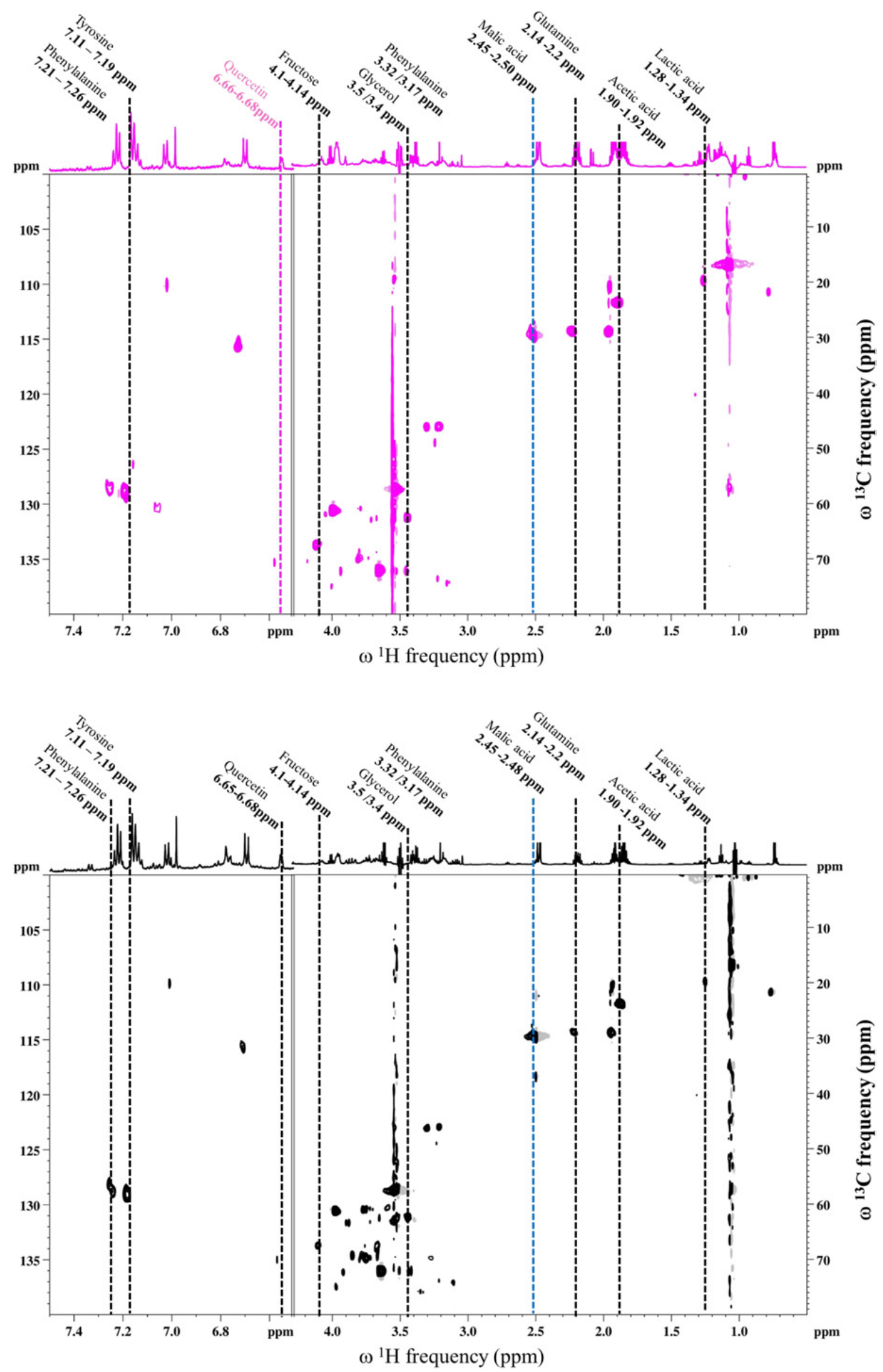

Figure 4. Two-dimensional ${ }^{1} \mathrm{H}_{-}{ }^{13} \mathrm{C}$ Heternouclear Single Quantum Coherence (HSQC) experiments, applying a home-made waterto-ethanol multipresaturation scheme [12] used to detect novel metabolites with the addition of a ${ }^{13} \mathrm{C}$ NMR dimension. Magenta: ${ }^{1} \mathrm{H}-{ }^{13} \mathrm{C}$ HSQC of large-scaled fermented wines with Saccharomyces Bayanus ex uvarum ES-U42 strain; Black: ${ }^{1} \mathrm{H}_{-}{ }^{13} \mathrm{C}$ HSQC of largescaled fermented wines with standard Saccharomyces Bayanus control; Blue: ${ }^{1} \mathrm{H}^{-13} \mathrm{C}$ HSQC of large-scaled fermented wines with Coinoculation of Non-Saccharomyces Candida zemplinina (Enartis Ferm) with S. cerevisiae $10 \mathrm{~N} 45$ strain. Bottom: ${ }^{1} \mathrm{H}-{ }^{13} \mathrm{C} \mathrm{HSQC}$ pulse program, with the addition of a multipresat module, prior to the INEPT polarization transfer module. 

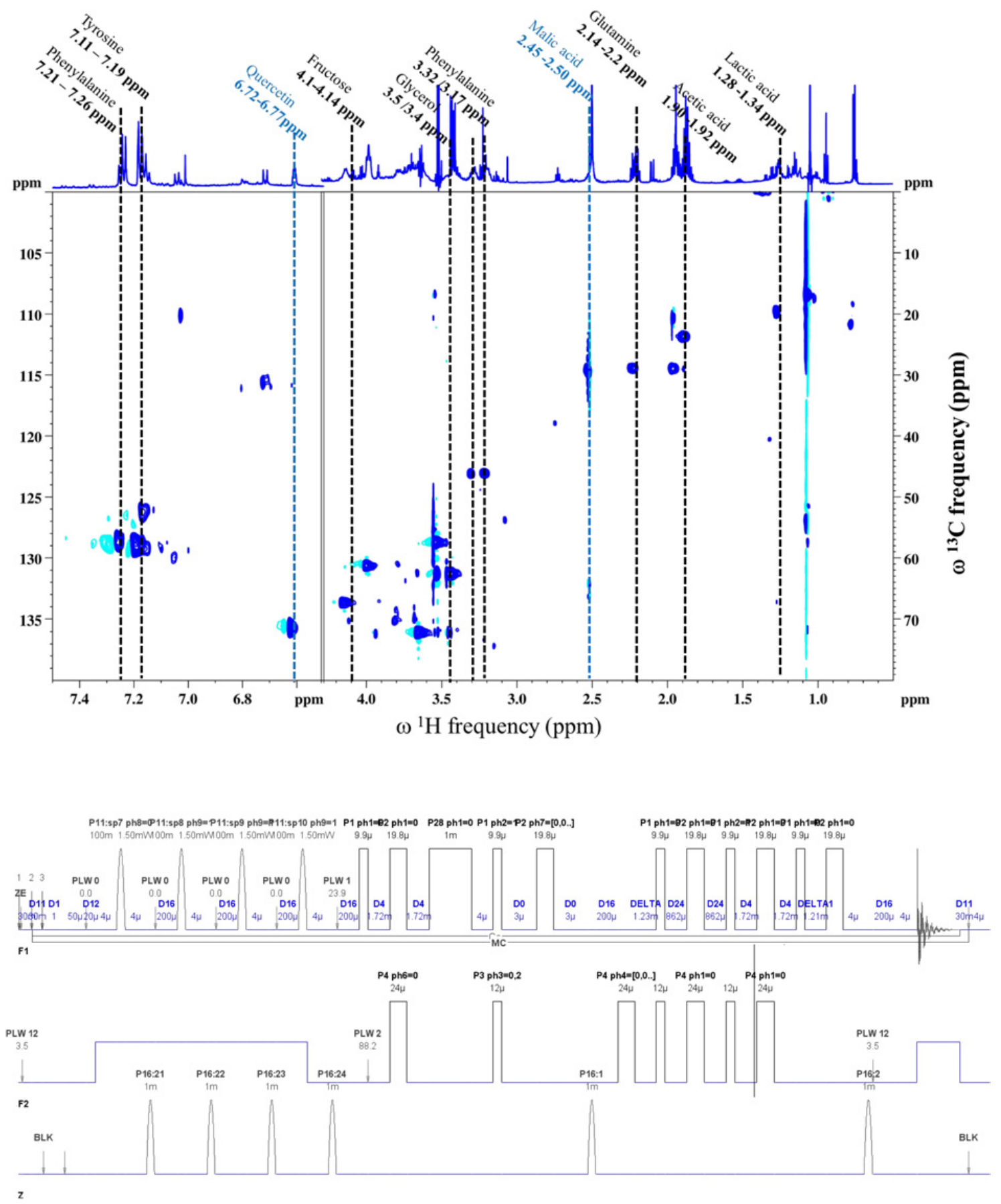

Figure 4. Continued.

for proteins [15] and recently to wine targeting [10], whereas for the later study, $20 \mathrm{mg} / \mathrm{L}$ of citric acid was used as external reference [10]. For the present study a set of external references were used for cross-check validation: $650 \mathrm{mg} / \mathrm{L}$ of acetic acid; $1436 \mathrm{mg} / \mathrm{L}$ of malic acid; $152 \mathrm{mg} / \mathrm{L}$ of sorbic acid; $49 \mathrm{mg} / \mathrm{L}$ of fumaric acid and $51 \mathrm{mg} / \mathrm{L}$ of shikimic acid. All external reference solutions were prepared at similar $\mathrm{pH}$ and buffer conditions with respect wine samples (see Materials and Methods). PULCON/NMR targeted analysis is stressed in Fig. 5 and Table 5.
From PULCON/NMR quantifications the following observations arise: At selected large-scale fermentation conditions, control and dealcoholized products present normal mean values of both acetic and shikimic acids. Normal mean values of malic acid were detected for both control and dealcoholized products of only Monte Xanic stocks. Acceptable mean values of fumaric acid were only obtained for dealcoholized wines from Casa Madero, fermented with co-inoculations $S$. cerevisiae $10 \mathrm{~N} 45+$ C. zeplinia. Controls and dealcoholized wines in all cases present low values of sorbic acid $(8-15 \mathrm{mg} / \mathrm{L}$ for $\mathrm{CM}$ 
Acetic acid (mg/l) PULCON/ NMR

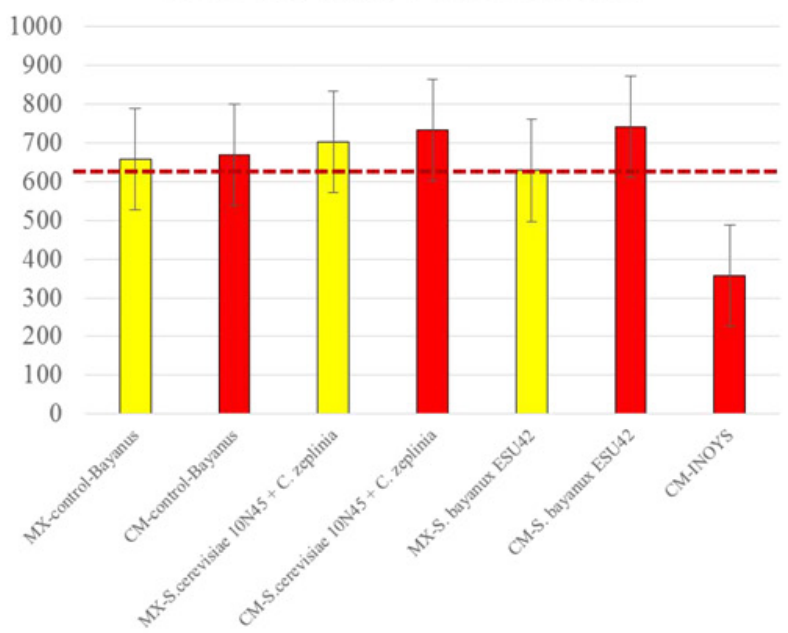

Malic acid (mg/l) PULCON / NMR

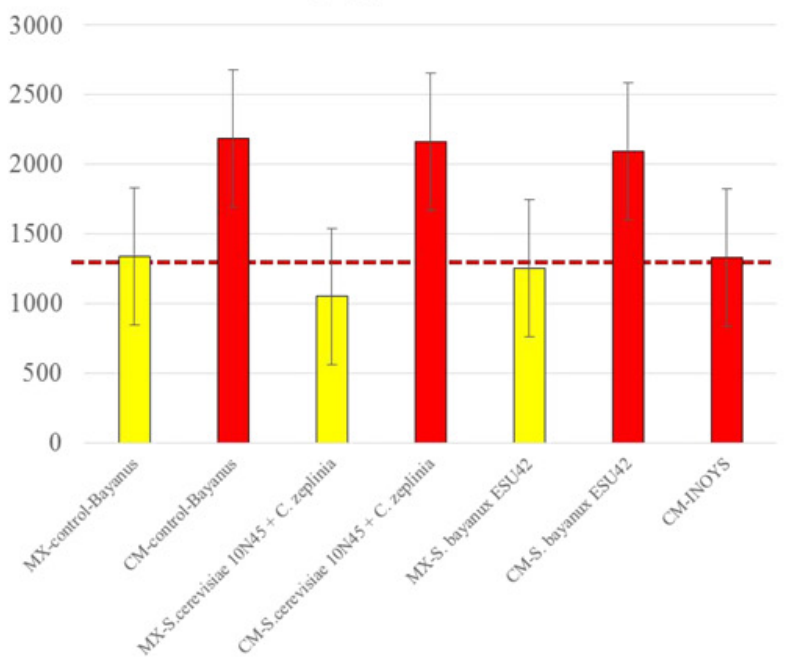

Sorbic acid (mg/l) PULCON/ NMR

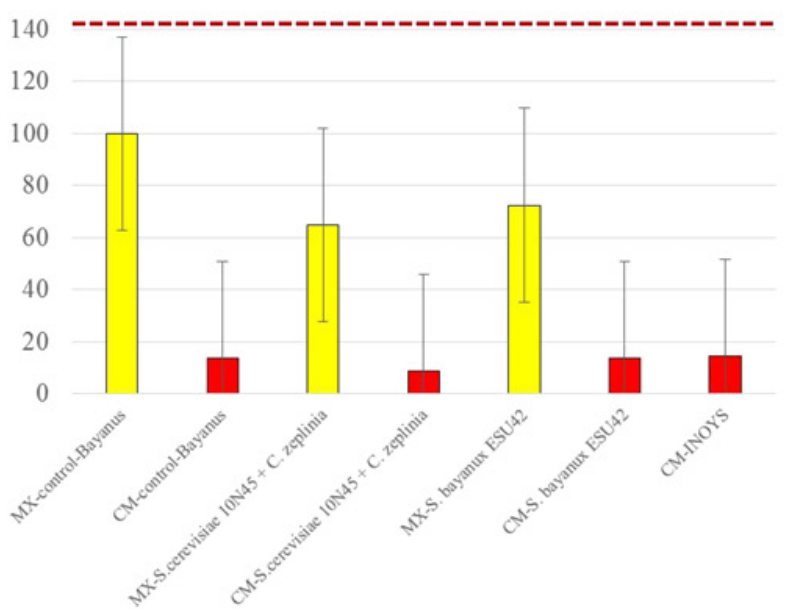

Fumaric acid (mg/l) PULCON / NMR

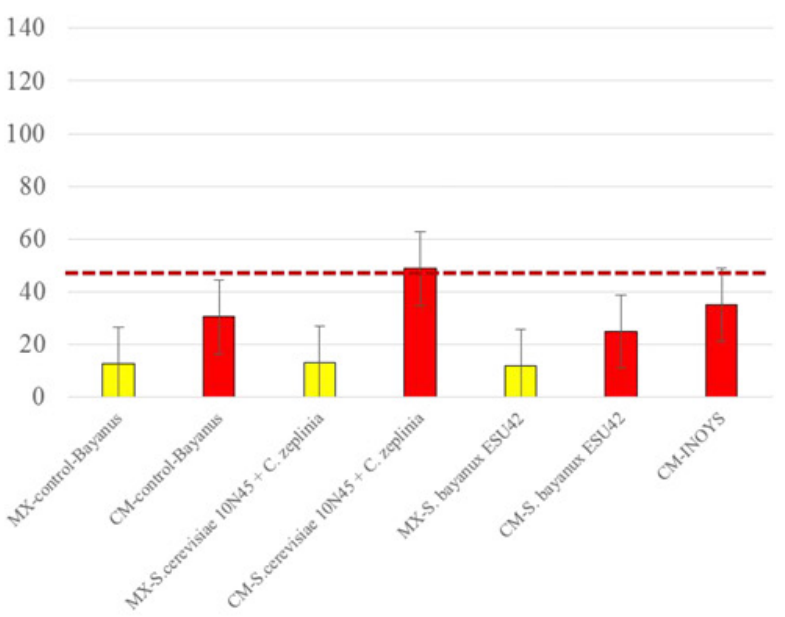

Shikimik acid (mg/l) PULCON / NMR

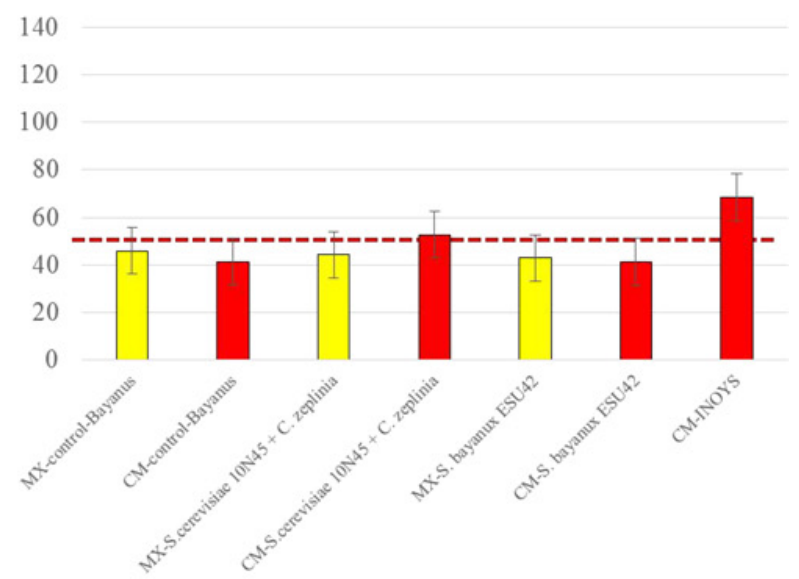

Figure 5. Quantification of acetic acid, malic acid, sorbic acid, fumaric acid and shikimic acid according to the PULCON/NMR method [15]. In all cases, an external reference of each metabolite, with known concentration, has been used for calibration. External standards were prepared in concentrations close to the OIV reference mean value (dotted red line) as follows: [acetic acid] $=650 \mathrm{mg} / \mathrm{L} ;[\mathrm{malic}$ acid $]=1436 \mathrm{mg} / \mathrm{L} ;$ [sorbic acid] $=152 \mathrm{mg} / \mathrm{L} ;[$ fumaric acid] $=49 \mathrm{mg} / \mathrm{L} ;[$ shikimic acid] $=51 \mathrm{mg} / \mathrm{L}$. 
Table 5. Quantification of assigned metabolites by PULCON/NMR analysis. Standard deviations per metabolite are as well described.

\begin{tabular}{|l|c|c|c|c|c|}
\hline & Shikimic (mg/L) & Fumaric (mg/L) & Sorbic (mg/L) & Malic (mg/L) & Acetic (mg/L) \\
\hline MX-control-Bayanus & 45.8 & 12.8 & 99.9 & 1338.3 & 657.3 \\
\hline CM-control-Bayanus & 41.3 & 30.4 & 13.5 & 2186.3 & 668.8 \\
\hline MX-S.cerevisiae 10N45 + C. zeplinia & 44.3 & 13.2 & 64.8 & 1050.2 & 703.2 \\
\hline CM-S.cerevisiae 10N45 + C. zeplinia & 52.6 & 48.8 & 8.6 & 2160.9 & 732.8 \\
\hline MX S. bayanux ESU42 & 42.9 & 12.0 & 72.4 & 1256.6 & 629.2 \\
\hline CM S. bayanux ESU42 & 41.2 & 24.8 & 13.6 & 2095.4 & 741.3 \\
\hline CM-INOYS & $\mathbf{6 8 . 4}$ & 35.2 & 14.4 & 1333.9 & 358.2 \\
\hline Desvest & $\mathbf{\pm 9 . 8}$ & $\pm \mathbf{1 3 . 9}$ & $\pm \mathbf{3 7 . 2}$ & $\pm \mathbf{4 9 2 . 6}$ & $\pm \mathbf{1 3 1 . 4}$ \\
\hline
\end{tabular}

samples; 64-100 mg/L for MX samples) with respect OIV accepted mean values $(150 \mathrm{mg} / \mathrm{L})$, suggesting a strong susceptibility of all samples to be unprotected against fungi or bacteria attacks [16].

\section{Conclusions}

A multitask NMR strategy is herein proposed to analyse alcohol reduction and oenological practice in wines produced with the first large-scale Non-Saccharomyces or non-conventional Saccharomyces fermentation processes. Standard metabolites were detected and quantified with the PULCON/NMR procedure and quality recommendations can be done as a function of selected fermentation scheme for reducing \%alc. (v/v). High-resolution two-dimensional ${ }^{1} \mathrm{H}-{ }^{13} \mathrm{C}$ HSQC with solvent multipresat have revealed novel resonances ready to be targeted and quantified with PULCON/NMR method, towards a not known accuracy in wines' quality control.

Authors acknowledge the Mexican Ministry of Science and Technology (CONACyT) for funding: CONACyT program No. 682 "Cátedras CONACyT", CONACyT program No. LN295321 "Laboratorios Nacionales" and CONACyT-México infrastructure grant: INFRA-2016 (269012) for funding Nuclear Magnetic Resonance experimental time.

\section{References}

[1] L.M. Schmidtke, J.W. Blackman, J. Food Sci. 71, R25 (2012)
[2] J. Röcker, S. Sturb, K. Elbert, M. Grossmann, Eur. Food Res. Technol. 242, 2051 (2016)

[3] OIV-OENO 394B-2012

[4] J. Varela, C. Varela, Curr. Op. Biotechnol. 56, 88 (2019)

[5] M. Gobbi, et al., Eur. Food Res. Technol. 239, 41 (2014)

[6] J.M. del Fresno, et al., Eur. Food Res. Technol. 243, 2175 (2017)

[7] S. Benito, et al., Eur. Food Res. Technol. 236, 29 (2013)

[8] J. Tronchoni, et al., Food Microbiol. 70, 214 (2018)

[9] M. Gobbi, et al., Food Microbiol. 33, 271 (2013)

[10] OENO-SCMA 17-618 "Quantitation of glucose, malic acid, acetic acid, fumaric acid, shikimic acid and sorbic acid in wine using proton nuclear magnetic resonance spectroscopy ( ${ }^{1} \mathrm{H}$ NMR)" (STEP 5)

[11] R. Godelmann, et al., J. Agric. Food Chem. 61, 5610 (2013)

[12] J.E. Herbert-Pucheta, et al., EDP Sciences, Bio Web Conf. (2019), doi: 10.1051/bioconf/20191202029

[13] A.G. Palmer III, J. Cavanagh, P.E. Wright, M. Rance, J. Magn. Reson. 93, 151 (1991)

[14] L.E. Kay, P. Keifer, T. Saarinen, J. Am. Chem. Soc. 114, 10663 (1992)

[15] G. Wider, L. Dreier, J. Am. Chem. Soc. 128, 2571 (2006)

[16] A. Tromp, W.A. Agenbach, S. Afr. J. Enol. Vitic. 2, 1 (1981) 